\title{
A Novel Technique of Closure of Scalp Defects under Tension
}

\author{
Shamshuddin Sr Patel ${ }^{1}$ \\ ${ }^{1}$ Department of Neurosurgery, National Neurosciences Centre, \\ Kolkata, West Bengal, India
}

J Neurosci Rural Pract 2021;12:450-451.

A 34-year-old lady underwent craniotomy and left frontal contusionectomy following a road traffic accident. Postoperatively, she had wound breakdown and underwent resuturing of the scalp on two separate occasions. These too gave way and she presented to us 1 month after the initial surgery with purulent discharge from the wound with exposed bone flap ( - Fig. 1A). Culture of the pus showed growth of pseudomonas and contrast enhanced computed tomography scan of the brain showed no evidence of any collection below the bone flap. She was put on antibiotics and underwent wound debridement, removal of the bone flap and infected granulation tissue, but on attempting to close the skin there was difficulty in approximating the margins. Due to scraping out of the wound margins, some galeal loss near the margins too was present. Further, the patient had not been prepared for a flap closure as we had not anticipated difficulty in closing the wound and had assumed that after removing the bone flap redundant skin would be present. Initially pulley sutures were placed in an attempt to draw the margins together, but they were cutting out due to poor soft tissue support below the skin at the margins. Hence, horizontal mattress sutures were placed and the suture was passed through small pieces of external ventricular drain (EVD) tubing to distribute the tension evenly over the margins and prevent skin necrosis ( - Fig. 1B). The wound got apposed well and healed satisfactorily when sutures were removed after 21 days ( - Fig. 1C).

Surgeons attempting to close scalp defects that are not unduly large use one of two techniques-(1) undermining the flap in the subgaleal plane or (2) employing pulley sutures to close the wound. Undermining the scalp decreases the tension on wound margins while closing the defect ${ }^{1}$ and Raposio et al have documented "progressive decrease in tension" with increasing amounts of undermining of the scalp. ${ }^{1}$ While this is the commonest technique employed by neurosurgeons to achieve wound closure in scalp defects, a subgaleal pocket is created where collections might accumulate. Hence, in our case, as there was documented infection, we did not attempt to undermine the upper margin of the wound posteriorly for fear of giving the septic process space to spread. Pulley sutures (employing the "far-near, near-far" technique) have the advantage of avoiding undermining and can be used in areas of poor tissue mobility. ${ }^{2}$ Wound necrosis at the margins has been reported with this technique ${ }^{2}$ particularly if all the "passes" of these sutures do not include the galea. In our cases as the galea was lost near the margins for a few millimeters (following scraping), this technique could not be

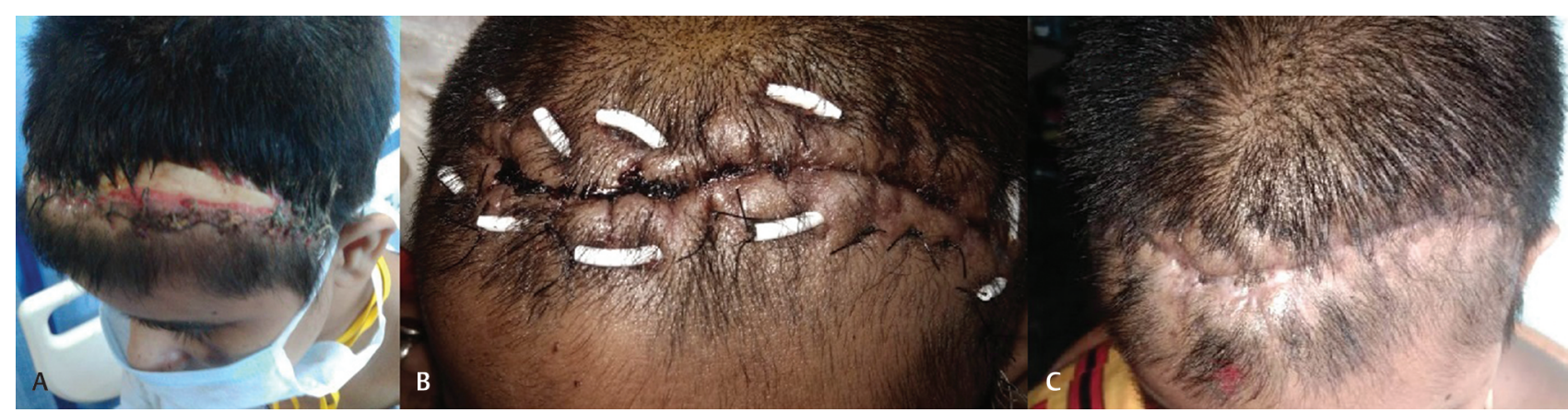

Fig. 1 Clinical photographs showing (A) wound dehiscence with the exposed bone flap and purulent discharge, (B) horizontal mattress sutures placed over external ventricular drain tubing to achieve skin approximation, and (C) satisfactory wound healing after suture removal.

published online April 1, 2021
DOI https://doi.org/ $10.1055 / \mathrm{s}-0041-1726658$ ISSN 0976-3147
(C) 2021. Association for Helping Neurosurgical Sick People. This is an open access article published by Thieme under the terms of the Creative Commons Attribution-NonDerivative-NonCommercial-License, permitting copying and reproduction so long as the original work is given appropriate credit. Contents may not be used for commercial purposes, or adapted, remixed, transformed or built upon. (https://creativecommons.org/licenses/by-nc-nd/4.0/).

Thieme Medical and Scientific Publishers Pvt. Ltd. A-12, 2nd Floor, Sector 2, Noida-201301 UP, India 
used (the near throws of the suture would be holding only epidermis and subcutaneous connective tissue and would cut through).

We then decided to employ horizontal mattress sutures to aid in skin approximation. As the needle would pass "far" from the margins in both directions, galeal support was ensured. The inherent disadvantage of horizontal mattress sutures-force deployed parallel to the wound marginswas mitigated by passing it through the soft EVD tubing to ensure cushioning of the epidermis from the tightness of the suture.

Though this kind of closure is commonly employed in secondary suturing of abdominal wound dehiscence, we did not find such a technique reported in scalp closure. As our patient had a satisfactory outcome both in terms of wound approximation and cosmesis, we feel this could be a useful technique for closing selected cases of scalp defects.

\section{Conflict of Interest}

None declared.

\section{References}

1 Raposio E, Nordström RE, Santi PL. Undermining of the scalp: quantitative effects. Plast Reconstr Surg 1998;101(5):1218-1222

2 Malone CH, McLaughlin JM, Ross LS, Phillips LG, Wagner RF Jr. Progressive tightening of pulley sutures for primary repair of large scalp wounds. Plast Reconstr Surg Glob Open 2017;5(12):e1592 